\title{
A study of the $\mathrm{Ca}$ antigen in epithelial tumours of the ovary
}

\author{
AM FERGUSON, H FOX* \\ From the Department of Pathology, St Mary's Hospital, Mainchester and the *Department of Pathology, \\ University of Manchester, Stopford Building, Oxford Road, Manchester M13 9PT
}

SUMMARY The expression of $\mathrm{Ca}$ antigen in ovarian epithelial tumours has been studied by an immunohistochemical technique using the $\mathrm{Ca} 1$ monoclonal antibody. The antigen was found to be present in some examples of each of the histological subtypes of ovarian epithelial neoplasms and was detected in benign, borderline and malignant tumours. It is concluded that the presence of $\mathrm{Ca}$ antigen is of no discriminatory value in the assessment of malignancy in ovarian epithelial neoplasms.

The Ca antigen was described by Ashall, Bramwell and Harris ${ }^{1}$ in 1982 as being present on the surface of a wide range of malignant cell lines whilst being absent from homogenates of normal adult and fetal tissues. McGee and his colleagues ${ }^{2}$ tested for this antigen, using the monoclonal IgM antibody $\mathrm{Ca} 1$, and found it to be present on the cells of most malignant human tumours but not on those of benign tumours: in normal tissues the antibody bound specifically only to transitional epithelium of the urinary tract and to the luminal surface of Fallopian tube epithelium.

Amongst the normal tissues studied by McGee and his coworkers were endometrium, cervix and ovary, all of which gave negative results, whilst amongst the tumours investigated were four ovarian cystadenomata, which also yielded negative results, and two ovarian serous cystadenocarcinomata which gave a positive result.

We report here a more detailed investigation of the distribution of $\mathrm{Ca}$ antigen in the normal ovary and in ovarian epithelial tumours of all degrees of malignancy. This study was undertaken with the principal aim of determining whether the presence of the $\mathrm{Ca}$ antigen was of any discriminatory value in (a) differentiating between the various histological subtypes of ovarian epithelial tumour, and, (b) distinguishing between benign and borderline, and between borderline and malignant epithelial ovarian neoplasms.

Accepted for publication 27 July 1983

\section{Material and methods}

\section{TISSUES}

Sections of 14 normal ovaries and of 107 epithelial ovarian tumours were examined. All tissues were from the files of the Pathology Department, St Mary's Hospital, Manchester and all had been fixed in formalin and embedded in paraffin. Most of the specimens were between one and three years old but in occasional cases-for example, mesonephroid carcinoma-it was necessary to use specimen blocks older than this, the oldest being $17 \mathrm{yr}$. Details of the number of cases in each category, together with the reproductive status, mean age and age range of the patients from whom they were obtained are shown in Table 1. It will be noted that we have included cases of ovarian endometriosis as the benign counterpart of malignant endometrioid neoplasms of the ovary: this is a controversial, but defensible, point of view. ${ }^{3}$

\section{REAGENTS}

Ca1 antibody was purchased from Wellcome Diagnostics. The rabbit peroxidase-labelled anti-mouse Ig was purchased from Mercia Brocades; fetal calf serum from Gibco and bovine albumin and trypsin from Sigma. The negative control antibody, an IgM raised in mice, was kindly donated by the Wellcome Foundation.

\section{IMMUNOPEROXIDASE TECHNIQUE}

Sections were cut at $5 \mu \mathrm{m}$, mounted on glass slides and stored overnight at $37^{\circ} \mathrm{C}$ prior to clearing in xylene, dehydrating in alcohol and washing in tap 
Table 1 Types of tumour studied and clinical data

\begin{tabular}{|c|c|c|c|c|}
\hline Tissue & No of cases & $\begin{array}{l}\text { No } \\
\text { postmenopausal }\end{array}$ & $\begin{array}{l}\text { Mean age of } \\
\text { patients }(y r)\end{array}$ & $\begin{array}{l}\text { Age range of } \\
\text { patients (yr) }\end{array}$ \\
\hline $\begin{array}{l}\text { Normal ovary } \\
\text { Serous cystadenoma } \\
\text { Borderline serous tumours } \\
\text { Serous adenocarcinoma } \\
\text { Mucinous cystadenoma } \\
\text { Borderline mucinous tumours } \\
\text { Mucinous adenocarcinoma } \\
\text { Seromucinous cystadenoma } \\
\text { Sero-mucinous borderline tumour } \\
\text { Endometriosis } \\
\text { Borderline endometrioid tumours } \\
\text { Endometrioid adenocarcinoma } \\
\text { Mesonephroid adenocarcinoma } \\
\text { Brenner tumour } \\
\text { Undifferentiated carcinoma }\end{array}$ & $\begin{array}{r}14 \\
14 \\
7 \\
14 \\
11 \\
10 \\
10 \\
2 \\
2 \\
7 \\
4 \\
7 \\
7 \\
8 \\
4\end{array}$ & $\begin{array}{l}0 \\
1 \\
1 \\
7 \\
3 \\
3 \\
6 \\
0 \\
1 \\
0 \\
2 \\
7 \\
5 \\
4 \\
2\end{array}$ & $\begin{array}{l}46 \cdot 4 \\
37 \cdot 0 \\
33 \cdot 0 \\
55 \cdot 8 \\
44 \cdot 2 \\
45 \cdot 7 \\
54 \cdot 5 \\
29 \cdot 0 \\
52 \cdot 0 \\
38 \cdot 9 \\
46 \cdot 9 \\
59 \cdot 3 \\
53 \cdot 9 \\
48 \cdot 0\end{array}$ & $\begin{array}{l}29-49 \\
22-56 \\
30-35 \\
31-77 \\
18-70 \\
15-75 \\
34-78 \\
28-30 \\
38-66 \\
24-50 \\
37-55 \\
52-71 \\
\overline{48}-58 \\
36-62\end{array}$ \\
\hline
\end{tabular}

water. The tissues were then subjected to trypsin digestion $(50 \mathrm{mg}$ trypsin in $10 \mathrm{ml}$ phosphate buffered saline (PBS) for $30 \mathrm{~min}$ at $37^{\circ} \mathrm{C}$ ) followed by three washes of 10 min each in PBS at room temperature. They were subsequently immersed in a methanol peroxide solution for $30 \mathrm{~min}$ at room temperature, washed in three changes of PBS and immersed in solution $\mathrm{A}$ for $30 \mathrm{~min}$ at room temperature. Solution A consisted of fetal calf serum $100 \mathrm{ml}$, bovine albumin powder $100 \mathrm{~g}$, sodium azide $1 \mathrm{~g}$ made up to one litre with PBS. The sections were then incubated with $\mathrm{Ca} 1$ antibody, diluted $1 / 16$, for one hour at room temperature and then washed with three changes of solution $A$ for 5-10 min each. This was followed by incubating for 30 min with a conjugate solution consisting of stock peroxidase-labelled anti-mouse $\mathrm{IgG}$ diluted $1 / 30$ with solution B (solution B consisting of $95 \mathrm{ml}$ of solution $A$ and $5 \mathrm{ml}$ of human serum of blood group $A B)$. The slides were washed in three changes of PBS for one minute each prior to exposure to the substrate solution (diaminobenzidine $5 \mathrm{mg}$ in $10 \mathrm{ml}$ PBS with $50 \mu$ l of hydrogen peroxide) for $10 \mathrm{~min}$ at room temperature. The slides were washed in slowly running tap water for 2-5 min, counterstained with haematoxylin, dehydrated in alcohols, cleared in xylene and mounted in XAM.

For each section incubated with the $\mathrm{Ca} 1$ antibody two other sections were cut consecutively from the same tissue and processed in exactly the same way except that in one the $\mathrm{Ca} 1$ antibody was replaced by PBS and in the other Ca 1 was replaced by a negative control antibody (IgM raised in mice). Sections from Fallopian tube were used as a positive control in each run.

\section{GRADING OF RESULTS}

Positively staining sections were graded in terms of the extent of positive staining rather than the strength of the staining. The slides were graded as $\mathrm{O}$
$=$ negative $++=$ few or moderate areas of positive staining; $++=$ extensive areas of positive staining.

\section{Results}

POSITIVE STAINING IN RELATIONSHIP TO

HISTOLOGICAL TYPE

These results are detailed in Table 2. Ca1 was detected in all histological forms of ovarian epithelial tumour though clearly occurring with considerably less frequency in the mucinous group of neoplasms than in any other histological subgroup.

\section{POSITIVE STAINING IN RELATIONSHIP TO \\ DEGREE OF MALIGNANCY}

The $\mathrm{Ca}$ antigen was detected in benign tumours, in tumours of borderline malignancy and in frankly malignant neoplasms, the only exception to this general rule being the absence of the antigen from benign mucinous tumours. In general terms malignant tumours tended to stain more extensively than did their benign counterparts but there were many exceptions to this rule, particularly notable in this respect being the benign Brenner tumours. In tumours of borderline malignancy there was no apparent relation between the degree of epithelial atypia and either the frequency or extent of positive staining whilst in the malignant tumours there was similarly no clear cut relation between staining patterns and the degree of tumour differentiation.

\section{PATTERN OF STAINING}

In the one normal ovary which gave a positive reaction for $\mathrm{Ca}$ antigen, staining was confined to a few cells in the thecal layer around a follicle.

In the epithelial tumours the staining was usually confined to the limiting membrane of cells, particularly those bordering cystic spaces or areas of necrosis. Staining of luminal contents was seen in a few borderline and malignant tumours, usually those 
Table 2 Results obtained by staining for Ca antigen

\begin{tabular}{|c|c|c|c|c|}
\hline & Number & ++ & + & 0 \\
\hline Normal ovary & 14 & 0 & 1 & 13 \\
\hline Serous cystadenoma & 14 & 8 & 5 & 1 \\
\hline Borderline serous tumour & 7 & 5 & 2 & 0 \\
\hline Serous adenocarcinoma & 14 & 13 & 1 & 0 \\
\hline Mucinous cystadenoma & 11 & 0 & () & 11 \\
\hline Borderline mucinous tumour & 10 & 1 & 0 & 9 \\
\hline Mucinous adenocarcinoma & 10 & 1 & 0 & 9 \\
\hline Sero-mucinous cystadenoma & 2 & 2 & 0 & 0 \\
\hline Borderline seromucinous tumour & 2 & 2 & 0 & 0 \\
\hline Endometriosis & 7 & 6 & 0 & 1 \\
\hline Borderline endometrioid tumours & 4 & 1 & 2 & () \\
\hline Endometrioid adenocarcinoma & 7 & 4 & 2 & 1 \\
\hline Undifferentiated carcinoma & 4 & 2 & 2 & 0 \\
\hline Mesonephroid clear cell adenocarcinoma & 7 & 3 & 3 & 1 \\
\hline Benign Brenner tumour & 8 & 4 & 4 & 0 \\
\hline
\end{tabular}

with extensive areas of cellular staining. Cytoplasmic staining was seen only in a small proportion of malignant tumours. In some areas of necrosis non-viable heavily positive staining cells were seen. The notable exception to these general patterns of staining was the group of Brenner tumours, these being the only benign neoplasms in which cytoplasmic staining was noted.

\section{Discussion}

It is clear from our results that the presence or absence of the $\mathrm{Ca}$ antigen is of no discriminatory value in distinguishing between the different histological subgroups of epithelial ovarian tumours: furthermore, testing for this antigen is of no value in the differentiation of benign from borderline, borderline from malignant or benign from malignant ovarian epithelial tumours. It had been hoped that if this antigen was expressed by malignant, but not by benign, ovarian epithelial neoplasms that this test would be of value in the assessment of tumours of borderline malignancy: unfortunately our hopes in this direction were not fulfilled.

The nature of the $\mathrm{Ca}$ antigen remains uncertain but the pattern of staining suggests that it is a secretory product. It has recently been shown ${ }^{4}$ that the Ca antigen is a glycoprotein of the mucin type and it is suggested that it tends to be expressed in many tumours and in some normal tissues to protect epithelial cells from the effects of excessive concentrations of hydrogen ions. The presence of this antigen in malignant tumours could thus be considered as a reflection of the metabolic features, such as glycolytic activity and lactic acid production, which are characteristic of such neoplasms. It is possible therefore that the poor expression of the $\mathrm{Ca}$ antigen in mucinous neoplasms is because of the fulfilment. by other mucin glycoproteins secreted by these tumours, of this protective role. Part of the argument for this view of the role of $\mathrm{Ca}$ antigen is, however, its expression by urinary tract transitional epithelium in response to the acid $\mathrm{pH}$ of urine. Brenner tumours, now known to be formed of uroepithelium, express this antigen in a similar manner to urinary tract epithelium despite the fact that, as benign tumours, they are unlikely to be exposed to an unphysiological hydrogen ion concentration. The functional role of $\mathrm{Ca}$ antigen must therefore remain sub judice.

It is of particular interest that $\mathrm{Ca}$ antigen is expressed most consistently by serous neoplasms. In this respect they resemble fallopian tube epithelium with which the epithelial component of serous tumours is considered to be homologous. ${ }^{3}$ Serous ovarian neoplastic amylase is present in much greater quantities in serous cyst fluids than in fluids from other types of ovarian epithelial tumours ${ }^{5}$ and it appears that serous tumours mimic physiologically. as well as morphologically, fallopian tube epithelium. The distribution of serous ovarian neoplastic amylase and $\mathrm{Ca}$ antigen is very similar in serous tumours, probably because both are markers of endosalpingeal functional activity.

We wish to thank Mrs L. Chawner and Mrs E Davies for technical assistance. AMF is in receipt of a research grant from the North West Regional Health Authority.

\section{References}

' Ashall F. Bramwell ME. Harris H. A new marker for human cancer cells. 1. The $\mathrm{Ca}$ antigen and the $\mathrm{Ca}$ antibody. Lancet 1982;ii: $1-6$

2 McGee JO'D. Woods JC, Ashall F. Bramwell ME. Harris H. A new marker for human cancer cells. 2. Immunohistochemical detection of the $\mathrm{Ca}$ antigen in human tissues with the $\mathrm{Cal}$ antibody. Lancet 1982:ii:7-10. 
${ }^{3}$ Fox H, Langley FA. Tumours of the ovary. London: Heinemann, 1976.

4 Bramwell ME, Bhavanandan VP, Wiseman G, Harris H. Structure and function of the $\mathrm{Ca}$ antigen. $\mathrm{Br} J$ Cancer 1983;48:177-83.

${ }^{5}$ van Kley H, Cramer S, Bruns DE. Serous ovarian neoplastic amylase (SONA): a potentially useful marker for serous ovarian tumors. Cancer 1981;48:1444-9.

Requests for reprints to: Professor H Fox, Department of Pathology, University of Manchester, Stopford Building, Oxford Road, Manchester M13 9PT, England. 